
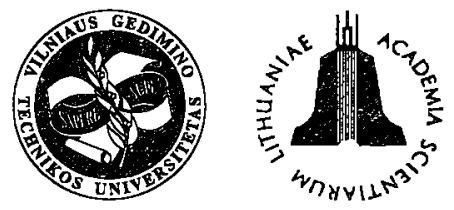

ISSN 1648-4142 TRANSPORT

http:/www.vtu.lt/english/editions

\title{
THE CRASH ENERGY ABSORPTION OF THE VEHICLES FRONT STRUCTURES
}

\author{
Paulius Griškevičius ${ }^{1}$, Antanas Žiliukas² \\ Dept of Mechanics of Solids, Kaunas University of Technology, \\ Kęstučio g. 27, LT-3004 Kaunas, Lithuania. Tel. (370 37) 324108 \\ Received 200211 02; accepted 20030228
}

\begin{abstract}
During the frontal crash the longerons absorb most energy of all vehicles construction elements. In order to analyse the energy absorbing capabilities of longerons under axial compression loading and to evaluate the influence of longerons geometrical characteristics and materials degradation on the vehicles safety experimental investigations and numerical calculations were performed. To assess the crashworthiness of longerons the main objective was to study the behaviour of thin-walled structural elements under axial loading conditions using the Finite Element (FE) model. The numerical FE models were created using the computer code LS-DYNA.

Two models of longerons were investigated with different sections shape and for each of them materials with the four different mechanical characteristics were applied. Validation of created FE model was performed according to the experimental investigation and the results were obtained of validated FE models of vehicles crash analysis [1].

The results of analyses show that the value of absorbed energy by the longerons of new vehicies exceeds the value of the oldest cars. The degradation of structures in the old cars has the significant influence on the absorbed energy.
\end{abstract}

Keywords: vehicles impact; longerons crashworthiness; energy absorption; axial compression; buckling.

\section{Introduction}

The main criteria of occupant safety are vehicles deceleration pulses and deformation of the occupant compartment. The management of the absorbed energy allows to increase the vehicle safety. The way of deformation of vehicle construction elements during the frontal impact and the value of the absorbed crash energy depends on vehicle construction, mechanical properties of materials and geometric characteristics of elements sections [2]. The ageing processes (metal fatigue, corrosion) of construction materials have the influence on vehicle safety, too. Over $80 \%$ in Lithuania registered cars are older than 12 years and in these cars defects of the vehicle body structural components (corrosion, deformation, cracks) exceed $5 \%$.

Computer Aided Engineering (CAE) techniques were used as a tool to evaluate this influence on the structural performance of vehicle construction. In this work the longeron has been analyzed which in the case of front crash is most important for vehicle safety of the front construction elements [1]. The angular orientation of the front collision is not analysed, when the longerons are bended and the quantity of the absorption energy by the longerons decreases [3-5].

Using the computer code LS-Dyna v.960 the FE models of the longerons were created. The geometric pa-

\footnotetext{
${ }^{1}$ E-mail: paulius.griskevicius@ktu.lt

${ }^{2}$ E-mail: antanas.ziliukas@mf.ktu.lt
}

rameters, materials characteristics and CAE crash analysis results (forces and absorbed energy) of longerons needed for the modelling and validation of FE models were obtained from Engineering Report [1].

Also the experimental testing has been used in this work to obtain some parameters needful to create $\mathrm{FE}$ model. The created FE models have been validated according to experimental results

\section{Energy Distribution in the Front Car Crash}

The new cars safety assessment was performed using the US-NCAP (United States - New Car Assessment Program) $(100 \%$ frontal crash at $56 \mathrm{~km} / \mathrm{h}$ into a rigid barrier) and Euro-NCAP ( $40 \%$ overlap offset frontal crash at $64 \mathrm{~km} / \mathrm{h}$ into a deformable barrier) requirements. $\mathrm{FE}$ models of two different cars were created and the structural crash analysis was performed in accordance with NCAP requirements. The results of these crash analyses had to be compared with the performance of longerons in the context of all components of vehicle construction.

The load paths during the frontal crash are presented in Fig 1.

The values of section forces obtained from Finite Element Analysis (FEA) models in vehicles front structures are presented in Fig 2 [1].

During the crash time the variable and averaged curve of the section forces obtained from created FE element model is presented in Fig 3. The maximum value of the 


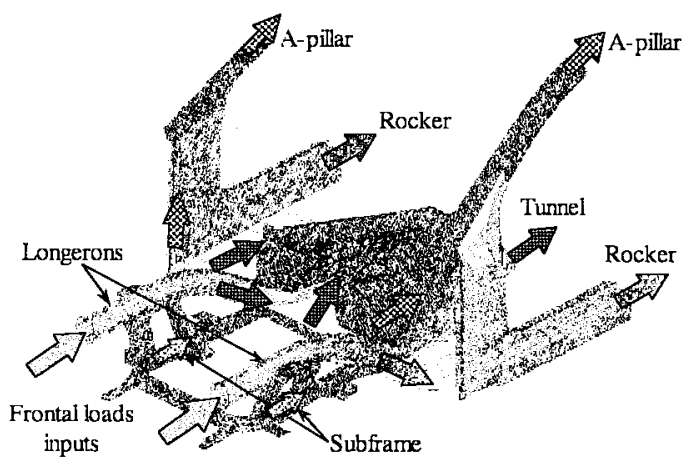

Fig 1. Load paths on car body elements during frontal impact

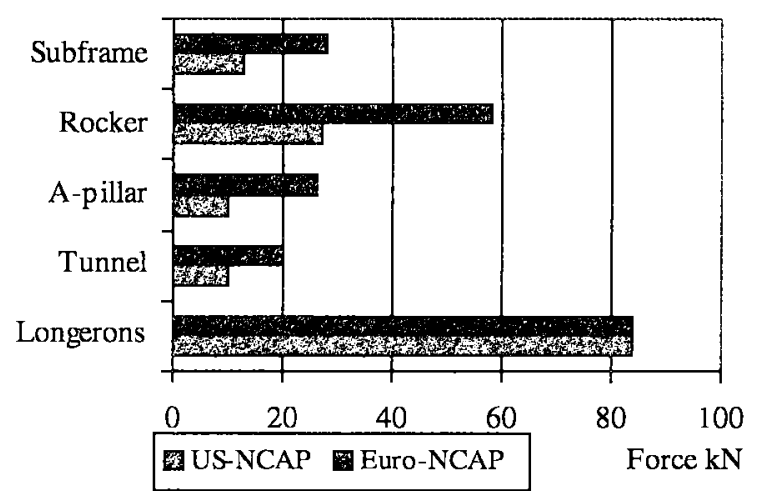

Fig 2. Typical section forces during frontal impact

averaged force characteristic is about $85 \mathrm{kN}$ and it is satisfied with forces value presented in the Fig 2 . The tested cars models [1] had the mass of $1300 \mathrm{~kg}$. In our created FE model of longeron the structural element with the designed length of $500 \mathrm{~mm}$ has been analysed. The AVC longeron used in the Report [1] is welded from two parts first - a hexagonal section $t=1,5 \mathrm{~mm} \mathrm{~L}=500 \mathrm{~mm}$, second - a hexagonal section $\mathrm{t}=1,3 \mathrm{~mm} \mathrm{~L}=2066 \mathrm{~mm}$. The mass attached to its end was $500 \mathrm{~kg}$ however if the crash forces exceed the critical buckling load, the results are approximately similar (with the end mass of $250 \mathrm{~kg}$ the value of absorbed energy was compared). The same values of longerons section forces in Fig 2 show that in both cases (US and Euro-NCAP crash tests) the longerons are maximally loaded.

The distribution of deformation energy during the frontal crash is presented in Fig 4 [1]. The figure shows that the longeron absorbed most energy of all front construction elements of vehicles. The calculated value $22 \mathrm{~kJ}$ of absorbed deformation energy by the modelled element is presented in Fig 5. This value satisfies the values presented in Fig 4. The same value of the absorbed energy allows us to assume that the created FE model of the longeron is right and that the other vehicle elements haven't significant influence on the longeron performance during the vehicle frontal crash.

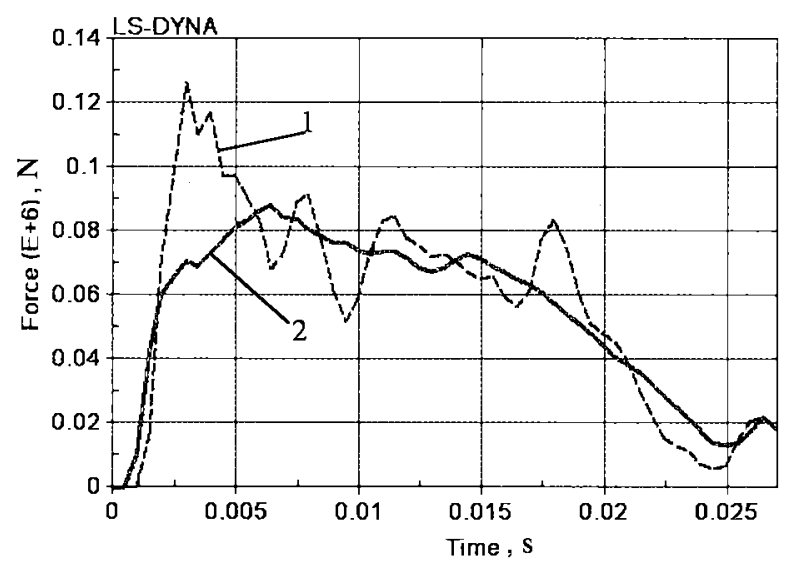

Fig 3. Section forces on the longerons obtained by FEA 1-calculated with $d t=0,00025 s ; 2$-average variable

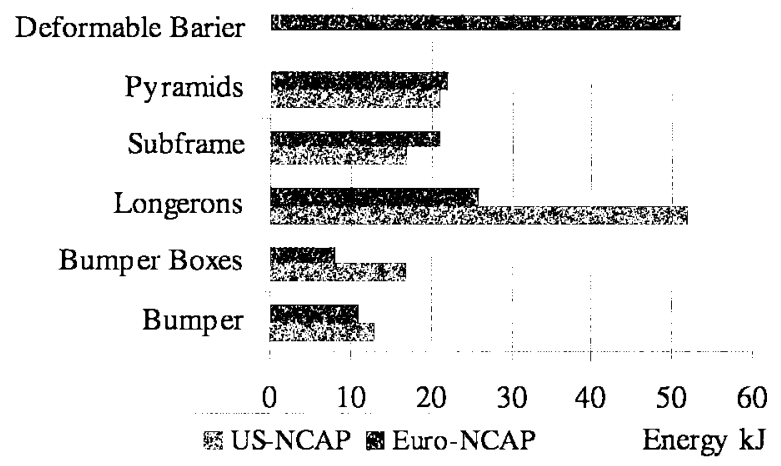

Fig 4. Energy distribution in the front car structures

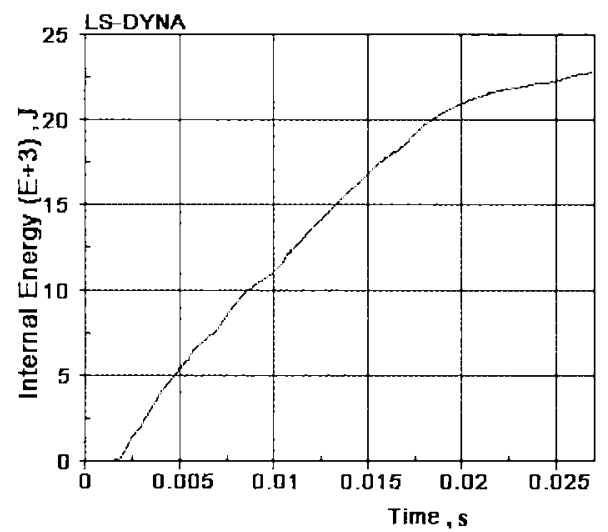

Fig 5. Sum of the absorbed energy in the longeron element calculated by the FE model

During the frontal crash in the rigid barrier with an impact speed $v$ and the vehicles mass $m$ the required deformation energy of structures is approximately equivalent to the kinetic vehicles energy before impact:

$$
E_{k}=\frac{m v^{2}}{2} \text {. }
$$

According to the calculated kinetic energy and the data of Fig 4 the obtained all crash energy distribution in 
the car structures and the evidence importance of the longerons are presented in Fig 6.

The differences between the energy distribution in the US and Euro-NCAP front crash tests are because in the Euro-NCAP tests there are higher velocities and used deformable barrier and energy distribution comes to one longeron.

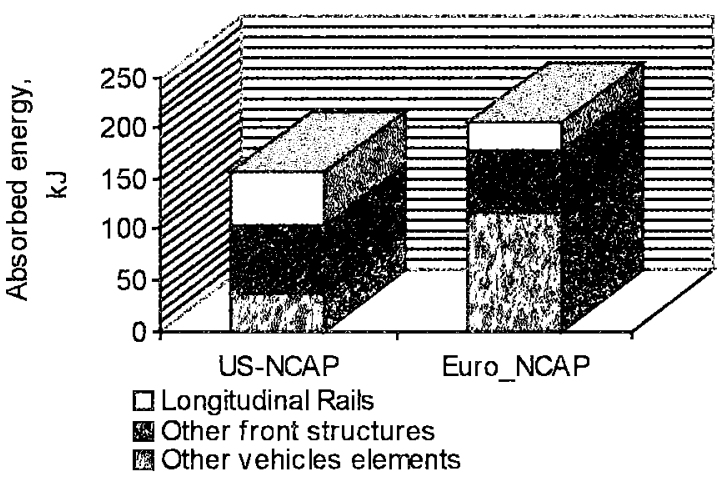

Fig 6. Energy distribution in the structures at the US and Euro NCAP front car crash tests

\section{Methods and Objects of Research}

To analyse the crashworthiness of longerons under axial compression loading and evaluate the influence of materials ageing to vehicles safety, experimental investigations and numerical calculations were performed. The Finite Element (FE) model was used to study the behaviour of thin-walled structural elements under impact.

The numerical FE models were created using the computer code LS-DYNA techniques with the nonlinear explicit analyses. The FE model of the longerons was performed using shell elements (Fig 7). With the shell elements also a rigid body was modelled and attached to the end of the longeron. In the center of a rigid body $500 \mathrm{~kg}$ lumped mass was attached. To the rigid body with the

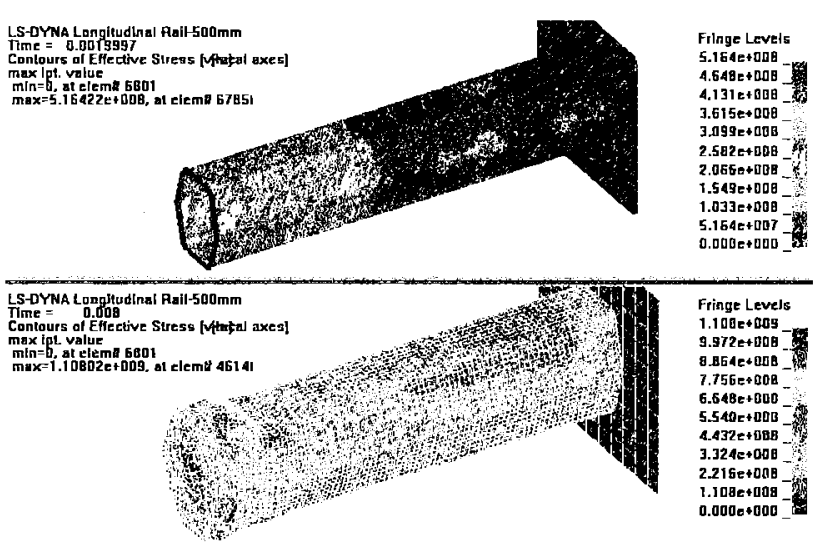

Fig 7. FE model of the Advanced Vehicles Concepts) AVC longeron and the first buckling wave after impact mass the initial velocity of $54 \mathrm{~km} / \mathrm{h}$ was applied. It provides the motion of the rigid body and longeron. After $0.002 \mathrm{~s}$ the front of the longeron impacts into the rigid wall. At this time the buckling of the longeron structures begins.

In the FE model the Belytschko-Tsay shell elements were used based on the Mindlin shell theory [6]. These elements used the plane stress material model. The input to the material model is Young's modulus, Poisson's ratio, the yield stress, and a true stress-effective plastic strain curve from the tensile test [1].

Mechanical properties of materials used in the FE model are presented in Fig 8. Steels with the four different mechanical properties were used. High Strength Low Alloy (HSLA 350/450) steels recently were commonly used for the structural components of new cars [7]. Today the Dual Phase (DP) group steels are increasingly used. For the longerons the DP 500/800 steel [7] is commonly used. The other two mechanical properties were obtained from the tensile test of the specimens of longerons (Fig 9).

The dynamic effects in the FE model eliminated using strain rate insensitive materials properties $[8,9]$.

The corrosion effect of the structural components of vehicles was estimated using the tensile tests of the corroded specimens. From tensile tests of corroded specimens it was obtained that the yield stress $\sigma_{Y}$ and true ultimate tensile stress $\sigma_{u}$ decrease ( $\sigma_{Y}$ - from $260 \mathrm{MPa}$ to $180 \mathrm{MPa}$ and $\sigma_{u}$ - from $360 \mathrm{MPa}$ to $300 \mathrm{MPa}$ ).

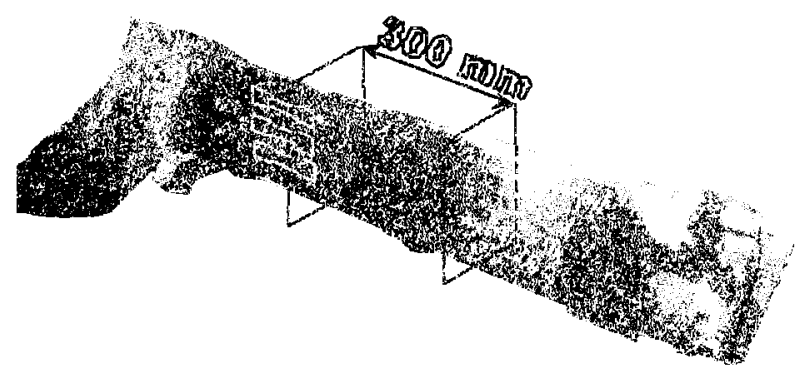

Fig 8. Preparing of specimens for the mechanical testing

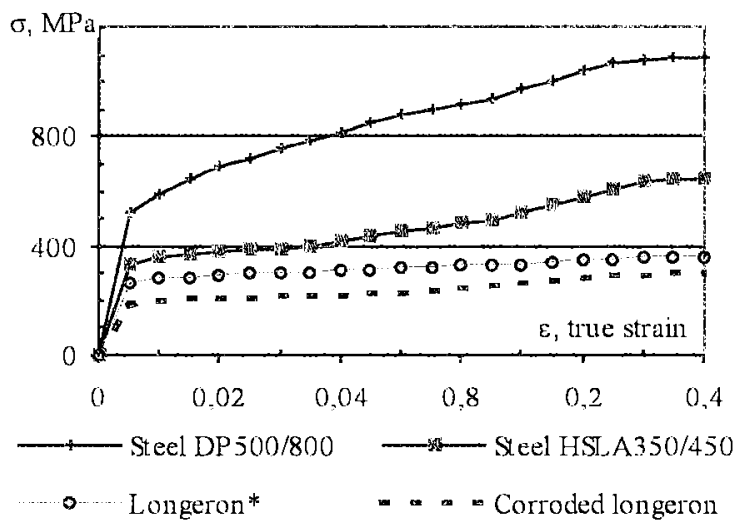

Fig 9. Mechanical properties of materials used in the FE models * - Longerons mechanical properties obtained from uniaxial tension test 
Four $300 \mathrm{~mm}$ length specimens (Fig 8) were prepared for the quasi-static axial compression test [10].

Crash energy absorption by the axially loaded longerons proceeds by the buckling process. The elements compressed by the axial compression at the critical load loss the stability of the equilibrium configuration of the structure. This process is called buckling. The thin shell structures during the axial compression had the local buckling. The axial compression of thin-walled cylinders is shown in Fig 10. Fig 11.

The buckling of the specimen (a) is presented in

The crashworthiness of structures indicates the value of absorbed energy per mass. One of indexes to measure crashworthiness is

$$
\eta_{c}=\frac{E_{d}}{M_{s}}
$$

where, $E_{d}$ is the absorbing energy of structure; $M_{s}$ is the mass of structure.

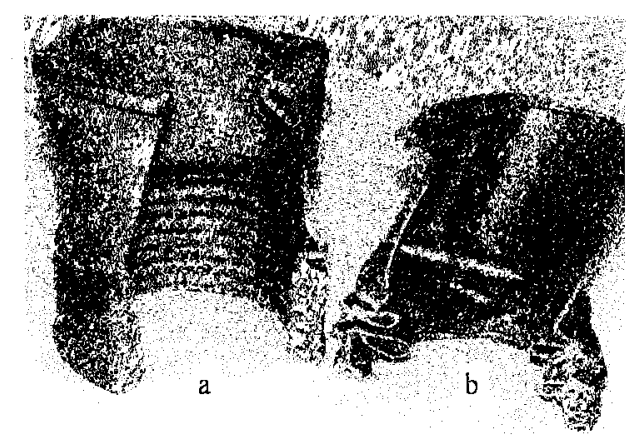

Fig 10. The axial compression of thin-walled cylinders a) specimen thickness $t=2,5 \mathrm{~mm}$ b) $t=1,5 \mathrm{~mm}$
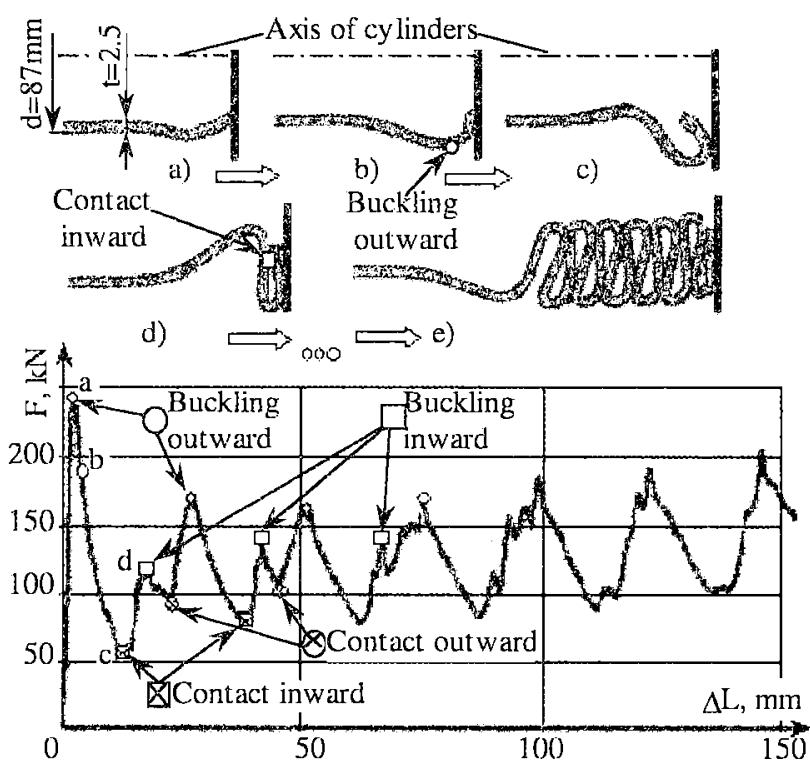

Fig 11. Buckling process of the thin-walled cylindrical specimen (Fig 10 a)
For the thin-walled sections having the same section shape, the crashworthiness index can be calculated by the following equation:

$$
\eta_{c}=\frac{F_{m l}}{A_{s} l},
$$

where, $F_{m}$ is the mean crash force; $A_{s}$ is the area of section; $l$ is the length of the thin-walled sections.

The mean crash force (Fig 12) is the mean value of crash force curve vs. collapse displacement, which indicates the whole energy of the thin-walled sections absorbed.

\section{Analysis of Results}

To estimate the influence of the corrosion on the crashworthiness of longerons and validate the FE model the experimental quasi-static axial compression tests were performed with the specimens of $300 \mathrm{~mm}$ length (Fig 13). These elements were axially compressed to the residual length of $200 \mathrm{~mm}$. From quasi-static compression test the relations between the compression load and displacements were obtained (Fig 12).

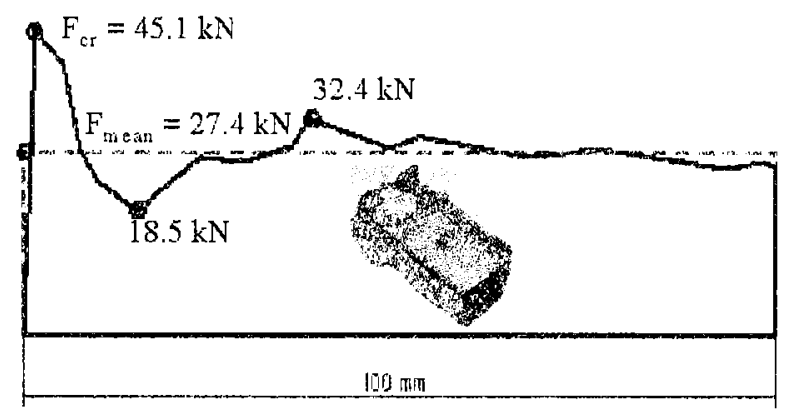

Fig 12. Axial-collapse characteristics of the specimen prepared of longeron

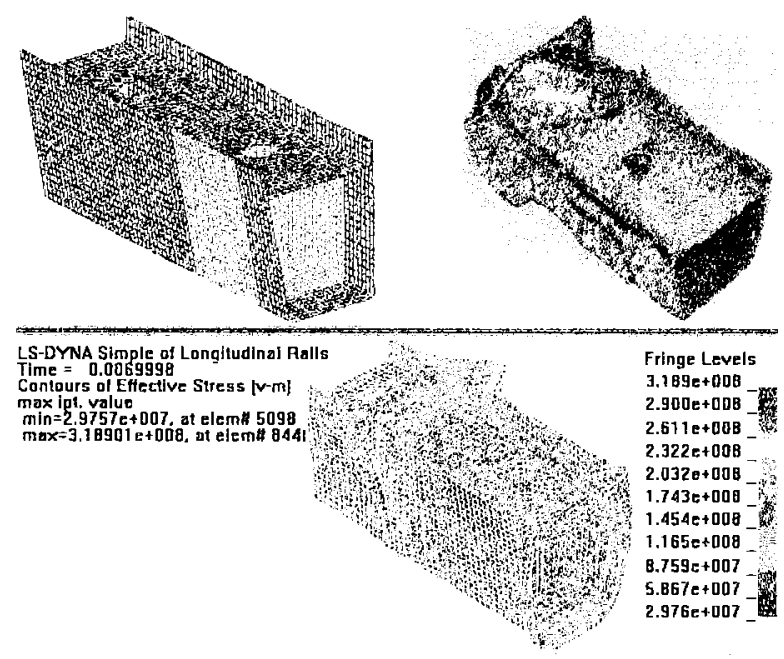

Fig 13. FE model and the specimen of the longeron 
The mean buckling loads $(27,4 \mathrm{kN})$ and work needed to compress a specimen of longeron were calculated from the diagram. This work approximately is equal to the absorbed deformation energy and calculated from the area under the diagram $\left(W=F \cdot \Delta l=27,4 \cdot 10^{3} \cdot 0,1=2,74 \mathrm{~kJ}\right)$.

Using the FE model (Fig 13) the obtained value of the absorbed energy at the moment of displacement equal to $0,1 \mathrm{~m}$ is practically the same as the obtained from experimental tests (the point (2,74 kJ) is matched in Fig 14).

The change of the mechanical properties of materials let to obtain the variation of the values of absorbed energy. From Fig 14 we could say that corrosion of the longerons could decrease the value of energy absorption 1.6 times. Also the proportion between the deformation energy during the mechanical tensile testing of specimens is 1.36 times.

Curve 2 in Fig 14 represents variation of the absorbed energy by the specimen that will be made of the HSLA 350/450 steel. The curve 1 shows the quantity of the absorbed energy by the AVC longeron made of DP 500/800 steel. The difference between the AVC and corroded longeron is about three times.

The difference between section areas of the corroded element and the AVC longeron is 1,25 . This means that the crashworthiness of the AVC longeron is 1.25 times bigger than the absorbed energy. To ensure the reason what is the influence of geometrical section and what are mechanical properties of materials performed the calculation of longerons specimen with the DP500/800 steel characteristics has been performed. Approximately the same value of the absorbed energy means that the geometrical influence between these models is equal to the proportion between their areas. In this case it is 1,25 times.

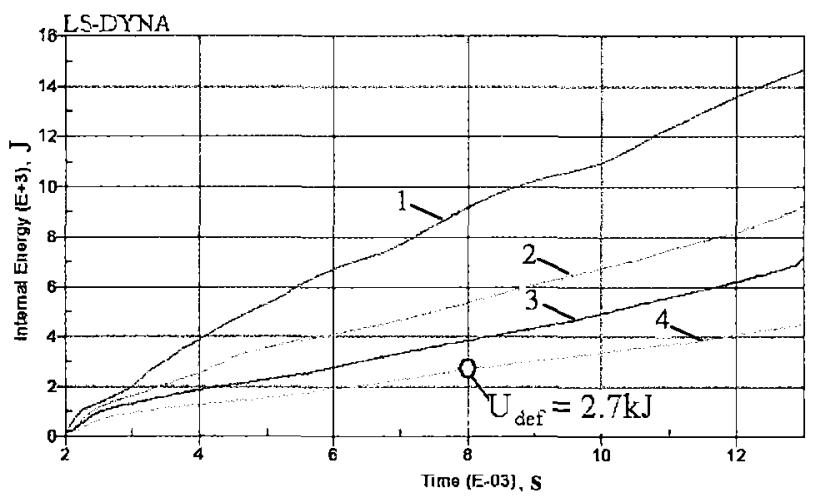

Fig 14. The crash energy absorption by the longeron models (1 - Steel DP 500/800 and geometrical characteristics from AVC longeron; 2 - Steel HSLA 350/450, geometrical characteristics from tested specimen of longeron; 3, 4materials mechanical and geometrical characteristics from tested specimen of longeron; 4 - corroded steels mechanical characteristics

\section{Conclusions}

The FE models results satisfied the experimental data.

1. Other construction components have low influence on the total absorbed energy of the longeron deformations. The FEM calculated value of the absorbed energy of the separate longeron element satisfies the absorbed energy values of the assembled longeron with the other construction components.

2. The value of the absorbed deformation energy in the experimental testing of the corroded longeron satisfies the results of FE model analyses. According to created FE model a man could easily by predict the lngerons behaviour of vehicles safety parameters using different mechanical properties of materials.

3 . The corrosion of longerons could decrease the value of energy absorption to 1.6 times. Also the proportion between the deformation energy during the mechanical tensile testing of the specimens is 1.35 times.

4. The difference of FE calculated total energy absorption between corroded longerons and modern AVC longerons is approximately three times.

\section{References}

1. Engineering Report. The design, materials, manufacturing, performance and economic analysis of the ULSAB-AVC (Ultra Light Steel Auto-Body - Advanced Vehicles Concepts). Porshe Engineering Service, Inc, 2001. 1348 p.

2. Lukoševičius, K; Žarnovskij, V. The restoration of an autombile deformed side members. Transport Engineering (Transportas), Vol XVI, No 1, 2001, p. 35-38 (in Lithuanian).

3. Kim, H. S.; Chen, W.; Wierzbicki, T. Weight and crash optimization of foam-filled three-dimensional " $S$ " frame. Computational Mechanics, 2002, 28, p 417-424.

4. Frei, P.; Kaeser, R.; Hafner, R. et al. Crashworthiness and Compatibility of Low Mass Vehicles in Collisions. SAE Technical Paper, No SAE-970122, 1997, p. 35-43.

5. Witteman, W. J., Kriens, R. F. C. Modelling of an innovative frontal car structure: similar deceleration curves at full overlap, 40 percent offset and 30 degrees collisions. In: Proceedings of the Sixteenth ESV Conference, Paper No 98S1-O-04, 1998, p. 194-212.

6. Hallquist, J. O., LS-DYNA, Theoretical Manual, (Livermore Software Technology Corporation), Livermore, CA, 1997. $498 \mathrm{p}$.

7. Flaxa, V; Shaw, J. Material Applications in ULSAB-AVC (Advanced Vehicles Concepts). In: Proceedings of the IBEC/ ATT 2002 Conference, SAE Paper, No SAE-2002-01-2074.

8. Karagiozovaa, D.; Jonesb, N. On dynamic buckling phenomena in axially loaded elastic-plastic cylindrical shells. International Journal of Non-Linear Mechanics, 2002, 37, p. $1223-1238$.

9. Langseth, M.; Hopperstad, O. S.; Hanssen, A. G. Crash behaviour of thin-walled aluminium members. Thin-Walled Structures, 1998, 32, p. 127-150.

10. Automotive Steel Design Manual. American Iron and Steel Institute \& Auto/Steel Partnership, Revision 6 2000. 747 p. 